Научная статья

УДК 332.142.6

DOI 10.18101/2306-630X-2020-2-27-32

\title{
АКТУАЛЬНЫЕ ВОПРОСЫ ГОСУДАРСТВЕННОЙ ПОЛИТИКИ В СФЕРЕ ЭКОЛОГИЧЕСКОЙ БЕЗОПАСНОСТИ
}

\author{
(C) Гилева Ирина Сергеевна \\ доцент кафедры теории и социологии управления, кандидат социологических наук, \\ Уральский институт управления — филиал \\ Российской академии народного хозяйства и государственной службы \\ Россия, 620144, г. Екатеринбург, ул. 8 Марта, 66 \\ gileva-is@ranepa.ru
}

\begin{abstract}
Аннотация. В статье рассматриваются особенности реализации государственной политики в сфере экологической безопасности в регионах. Вопросы экологической безопасности становятся актуальными ввиду общемировых тенденций, связанных с ухудшением состояния климата в целом в мире, стремительном истощении природных ресурсов, пересмотре принципов и подходов к действиям государств в отношении экологической ситуации отдельных стран. Основной особенностью современной экологической политики становится учет важнейших стратегических ориентиров, специфики развития конкретных территорий. Сегодня имеется положительный и даже инновационный опыт в реализации проектов и мероприятий экологической политики в отдельных регионах, который можно использовать и в Свердловской области. Так, например, в отдельных регионах инициированы и реализуются проекты, направленные на повышение экологической грамотности, активности и ответственности граждан за экологическую обстановку. Эти проекты связаны с информированием о пунктах приема и утилизации бытового мусора, с экологическим просвещением и популяризацией «зеленого предпринимательства», поддержкой и восстановлением экосистемы по всему миру и т. п. В дальнейшем необходимо только поступательное и расширительное развитие мер и направления государственной экологической политики, которые будут способствовать стабилизации ситуации в сфере экологической безопасности страны.

Ключевые слова: экологическая политика; экологический рейтинг; экологические угрозы; экологическая безопасность; окружающая среда; мировая экосистема; Agenda XXI; экологические ориентиры; экологические проекты; «Зеленая кнопка»; зеленое предпринимательство.
\end{abstract}

\section{Для цитирования}

Гилева И. С. Актуальные вопросы государственной политики в сфере экологической безопасности // Евразийство и мир. 2020. № 2. С. 27-32.

В течение многолетней истории развития нашей цивилизации взаимодействие с окружающей средой строилось по-разному. Первоначально наблюдалась «невысокая эксплуатация» всех возможных природных ресурсов, затем этот процесс приобрел существенную активность, постепенно стали возникать вопросы об экологической безопасности и необходимости сохранения мировой экосистемы. Лишь во второй половине XX в. на государственном уровне, в политическом плане, был поставлен 
вопрос об охране окружающей среды, так как ее загрязнение в результате жизнедеятельности человечества достигло критического уровня. Так, например, в 1992 г. 179 мировых государств приняли программу всемирного сотрудничества, которая в большей своей части направлена на достижение высокого качества окружающей среды ${ }^{1}$.

Российское состояние экологической безопасности характеризуется преимущественно негативными оценками. По оценкам экспертов, «около $15 \%$ территории нашей страны ежегодно отмечается как находящиеся в критическом или околокритическом состоянии», более того уже практически «60\% населения России живет в неблагоприятных экологических условиях» [1]. В Свердловской области экологическая ситуация еще более критическая. По результатам ежегодного составления «Экологического рейтинга федеральных округов Российской Федерации», Свердловская область находится на 85 -м месте 2 .

Поэтому неслучайно, что в последние годы экология стала сферой повышенного интереса для исследований в области науки, теории и практики управления. В настоящее время новые стратегические ориентиры России на срок до 2024 г., сформулированные в указе Президента № 204 «О национальных целях и стратегических задачах ${ }^{3}$, достаточно четко определяют критерии развития страны в сфере экологии, к которым относят «эффективное обращение с отходами, кардинальное снижение уровня загрязнения атмосферного воздуха в крупных промышленных центрах, повышение качества питьевой воды для населения, экологическое оздоровление водных объектов и прочее» ${ }^{4}$.

Таким образом, вопросы организации эффективной работы в рамках экологической безопасности, реализация эффективных мероприятий экологической политики имеют сегодня высочайшую значимость, социально-экономическую ценность, политическую окраску. Сегодня инструменты экологической политики становятся важными мерами по достижению глобальных приоритетов в системе стратегических экологических ориентиров для России на ближайшие годы.

Сфера экологической безопасности всегда представляла большой научный интерес. В течение многих десятилетий исследованием проблем экологической безопасности занимались в основном экологи, социологи, политологи. О. С. Колбасов, А. И. Костин, В. А. Смышляев исследовали общие аспекты понятия и содержания экологической безопасности. В работах А. С. Астахова, Е. Я. Диколенко, В. А. Харченко рассматриваются особенности реализации экологической политики в отношении отдельных групп ресурсов - воздух, вода и пр. В исследованиях М. Ю. Лучинкина, М. В. Пономарева рассматриваются ключевые направления

\footnotetext{
${ }^{1}$ Повестка дня на 21 век / Agenda XXI. [Электронный pecypc]. URL: http://www.r-komitet. ru/s_i_d/agenda21/index.htm (дата обращения: 02.11.2020).

${ }^{2}$ Национальный экологический рейтинг регионов РФ по итогам осени 2018 года [Электронный ресурс]. URL: http://www.greenpatrol.ru/ru/novosti/nacionalnyy-ekologicheskiyreyting-regionov-rf-po-itogam-oseni-2018-goda (дата обращения: 05.11.2020).

${ }^{3} \mathrm{O}$ национальных целях и стратегических задачах развития Российской Федерации на период до 2024 года: указ Президента Российской Федерации от 07.05.2018 № 204. В данном виде документ опубликован не был. Доступ из справ.-правовой системы «КонсультантПлюс».

${ }^{4}$ Там же.
} 
Гилева И. С. Актуальные вопросы государственной политики

в сфере экологической безопасности

и особенности деятельности органов власти в сфере экологической безопасности. Зарубежный опыт решения проблем в сфере экологической безопасности исследован в работах Т. Л. Мироненко, А. Г. Юдина.

Важнейшим направлением исследования и предотвращения современных проблем в сфере экологической безопасности является определение данного понятия. Обращение внимания к данной категории в России было связано с глобальной аварией на Чернобыльской АЭС. Сегодня под экологической безопасностью понимают результат деятельности соответствующих органов власти, связанный с обеспечением безопасности при осуществлении потенциально опасных видов деятельности с формулировкой экологических приоритетов в различных сферах общественной жизнедеятельности, с предотвращением и снижением экологических последствий от различных видов деятельности, в том числе и после чрезвычайных ситуаций и пр. [2].

Поэтому экологическая безопасность — это особое состояние защищенности важнейших экологических интересов и потребностей граждан, прежде всего прав на чистую и здоровую окружающую среду, ее отдельные виды ресурсов, являющееся результатом функционирования особой системы важнейших элементов (экологии и экологической безопасности), которые выполняют в современное время конкретные функции [3].

Экологическая политика - это целенаправленная и систематическая деятельность органов государственной власти различных уровней, «направленная на охрану и оздоровление окружающей среды, рациональное использование и возобновление природных ресурсов, сохранение и развитие социальной сферы, обеспечивающей нормальную жизнедеятельность и экологическую безопасность человека, среды его обитания» [4]. Экологическая политика стала сегодня неотъемлемой частью внешней и внутренней политики государств, в том числе и России, и включает, как правило, ряд основных направлений: оптимизацию использования природных ресурсов в процессе общественного производства, охрану природы от негативных последствий деятельности человека, экологическую безопасность населения.

Основная цель экологической безопасности состоит в достижении устойчивого развития с созданием благоприятной среды обитания и комфортных условий для жизнедеятельности и воспроизводства населения, обеспечения охраны природных ресурсов и биоразнообразия, предотвращения техногенных аварий и катастроф.

Анализ общедоступных публикаций по экологическим проблемам в Свердловской области показал, что ключевыми являются загрязнение атмосферного воздуха, недостаточная очистка сбрасываемых отходов в водные бассейны Свердловской области и, как следствие, большое скопление донных отложений, а также загрязнение отходами в виде свалок, большого объема земель Свердловской области. Исходя из проблем, мы видим, что необходимо более грамотное выстраивание всей экологической политики в Свердловской области, так как «точечно» решить скопившиеся проблемы уже не удастся. В связи с этим необходимы разработка новых механизмов деятельности, создание специальных мер, которые будут направлены на все сферы экологической безопасности.

Полезен в этой связи может быть опыт других стран и регионов России. Среди важнейших и уже апробированных способов отмечаются альтернативные техноло- 
гии очистки воды без применения хлорирующих средств, а также дуальная система сортировки мусора, разработанная и применяемая во многих европейских странах. Конечно, нужны более кардинальные меры в отношении обеспечения экологической безопасности, но это все же является результатом долгосрочной государственной политики, ориентированной на инновационные методы и подходы к ее понимания и ведению. Так, например, недавно была опубликована новость, что Великобритания готова после 2035 г. отказаться от машин на дизеле и бензине. И хотя эксперты прогнозируют время, когда в Британии невозможно будет купить автомобиль, который работал бы на дизеле или бензине, не ранее 2050 г. — такая инициатива говорит о принципиально новом подходе и высокой степени готовности властей страны изменить экологическую ситуацию ${ }^{1}$.

В России, безусловно, меры не столь кардинальны, но тем не менее они существуют и демонстрируют растущую популярность как у субъектов реализации государственной политики в сфере экологии, так и среди заинтересованных участников, граждан, предпринимателей. Среди механизмов проведения политики в сфере экологической безопасности на территории, России, в качестве наиболее интересного можно выделить проект «Зеленая кнопка», который представляет собой электронный ресурс, информирующий население об имеющихся на территории региона пунктах приема и утилизации масел, стекла, макулатуры, ламп, шин, батареек, пластика, аккумуляторов ${ }^{2}$. Проект имеет все возможности для улучшения экологической обстановки в области.

В центральном федеральном округе регулярно проводится акция «Электроник», основной целью которой является «экологическое образование и просвещение населения, воспитание ответственного потребления, проявление активной гражданской позиции в стремлении сохранить окружающую среду для последующих поколений, а также стимулирование развития «зеленого предпринимательства» ${ }^{3}$. В ходе акции люди избавляются от электрических и электронных товаров, уже не нужных в быту, но которые еще работают, а потому их жалко выбросить. Всю собранную технику передают общественным организациям инвалидов, волонтерским, экологическим, патриотическим и туристическим организациям. Акция «Электроник» направлена именно на помощь людям и общественным объединениям ${ }^{4}$.

Также разработан и реализуется проект «Маракуйя» через одноименную платформу имеется возможность восстанавливать леса в самых уникальных местах планеты: в национальных парках и заповедниках, сохраняя тем самым среду обитания редких видов животных и птиц; в городских парках, улучшая экологическую ситуацию мегаполисов; на землях лесного фонда. Все этапы проекта, от посадки

\footnotetext{
${ }_{1}^{1}$ Таиров Р. Великобритания запретит продажи новых машин с бензиновыми двигателями [Электронный pecypc]. URL: https://www.forbes.ru/newsroom/obshchestvo/392499velikobritaniya-zapretit-prodazhi-novyh-mashin-s-benzinovymi (дата обращения: 12.10.2020). ${ }^{2}$ O проекте «Зеленая кнопка» [Электронный ресурс]. URL: http://ecorzn.ru/green_button/ (дата обращения: 12.10.2020).

${ }^{3}$ В Московской области 14 сентября 2015 г. стартует экомарафон «Переработка» [Электронный pecypc]. URL: http:/www.greenpatrol.ru/en/node/277740 (дата обращения: 12.10.2020).

${ }^{4}$ Год экологии в России: информационные материалы. Рязань; 2016. 11 с.
} 
Гилева И. С. Актуальные вопросы государственной политики в сфере экологической безопасности

саженцев до последующего пятилетнего ухода, осуществляются высококлассными специалистами ${ }^{1}$.

Говоря о международном опыте в рамках политики переработки отходов можно отметить введение «дуальной системы», обеспечивающей разделение мусора на две группы: сортируемый мусор и мусор, не подлежащий сортировке. При такой системе все платят за свой мусор и несут ответственность за сортировку, что обеспечивает возможность последующей переработки отходов, снижение отрицательного влияния на окружающую среду [5].

Подводя итог, можно сказать, что для Свердловской области актуальным и возможным направлением государственной политики в сфере экологической безопасности должно стать совершенствование нормативно-правовой и методической базы, позволяющей осуществить в регионе необходимые мероприятия, связанные с ликвидацией прошлого экологического ущерба с учетом задач сохранения и восстановления природной среды. Необходимо увеличение затрат на осуществление проектов в сфере экологической безопасности возможно с привлечением частных инициатив, а также поиск компромисса со всеми промышленными предприятиями, при котором они будут заинтересованы в отсутствии нанесения ущерба окружающей среда.

\section{Литература}

1. Путин В. В. Экологическую ситуацию на 15\% территории России можно считать критической [Электронный ресурс]. URL.: https://dinfox.ru/news/195/social/society/66553putin-ekologiceskuu-situaciu-na-15-territorii-rossii-mozno-scitat-kriticeskoj (дата обращения: 05.11.2020).

2. Астахов А.С., Диколенко Е. Я., Харченко В. А. Экологическая безопасность и эффективность природопользования. Вологда: Инфра-Инженерия, 2018. 323 с.

3. Графкина М.В., Михайлов В. А., Иванов К. С. Экология и экологическая безопасность: учебник. М.: Форум, 2017. 149 с.

4. Круглов В.В., Вараксин В.В.О государственной экологической политике в Российской Федерации // Российский юридический журнал. 2015. № 1. С. 26-31.

5. Мироненко Т. Л. Особенности экологической политики государства (на примере США и ФРГ) // Полития. 2016. № 1. С. 161-175.

\section{TOPICAL ISSUES OF STATE POLICY IN THE FIELD OF ENVIRONMENTAL SECURITY}

Irina S. Gilyova

Cand. Sci. (Sociol.), A/Prof. of Theory and Sociology of Management Department, Ural Institute of Management - Branch of the Russian Academy

of National Economy and Public Service,

66, 8 Marta St., Ekaterinburg 620144, Russia

gileva-is@ranepa.ru

\footnotetext{
1 Что такое проект «Маракуйя» [Электронный ресурc]. URL.: https://www.maraquia.com/ru/ (дата обращения: 12.06.2020)
} 
Abstract. The article deals with the specifics of implementing state policy in the field of environmental security in regions. Environmental security issues are becoming relevant in view of global trends associated with the deterioration of world climate, the rapid depletion of natural resources, the revision of the principles and approaches of states in relation to the environmental situation in individual countries. Modern environmental policy is characterized by the regard of the most important strategic guidelines, the specifics of development of individual territories. To date there is a positive and even innovative experience in implementing the projects and measures of environmental policy in certain regions, which can be used in the Sverdlovsk Oblast. For example, in certain regions projects have been initiated for increasing environmental awareness, activity and responsibility of citizens for the environmental security. These projects involve the collection and disposal of household waste, environmental education, popularization of "green entrepreneurship", support and restoration of the world ecosystem, etc. It is necessary to use in the future only progressive and extensive measures for the development of state environmental policy, which will help stabilize the situation in the field of environmental security in the country.

Keywords: environmental policy; environmental rating; environmental threats; environmental safety; environment; global ecosystem; Agenda XXI; environmental guidelines; environmental projects; "Green button"; green entrepreneurship.

Статья поступила в редакцию 15.11.2020; одобрена после рецензирования 07.12.2020; принята к публикации 11.12.2020. 